Pak. j. sci. ind. res. Ser. B: biol. sci. 2021 64B(2) 192-197

\title{
Correlation Studies of Starch Pasting Properties Determined Through Rapid Visco Analyzer
}

\author{
Ayesha Riaz $^{\mathrm{ab} *}$ and Imran Pasha ${ }^{\mathrm{a}}$ \\ anational Institute of Food Science and Technology, University of Agriculture, Faisalabad, Pakistan \\ ${ }^{b}$ Department of Food Science and Technology, Gomal University, D.I. Khan-29050, Pakistan \\ (received May 5, 2017; revised January 10, 2019; accepted April 12, 2019)
}

\begin{abstract}
In present study, pasting properties of wheat varieties were investigated through rapid visco analyzer (RVA). Starch content was determined by Megazyme kit method varied from 68.88 to $72.73 \%$. Pasting properties indicated variability from 65.25 to $67.80{ }^{\circ} \mathrm{C}$ (pasting temperature), 3.22 to $6.00 \mathrm{~min}$ (peak time), 1330 to $1784 \mathrm{cP}$ (peak viscosity), 645 to $1002 \mathrm{cP}$ (trough viscosity), 1799 to $2565 \mathrm{cP}$ (final viscosity) 685 to $782 \mathrm{cP}$ (breakdown viscosity) and 1154 to 1563 (setback viscosity). Starch content and seven parameters observed from RVA profiles of various wheat varieties were evaluated for their interdependence. Starch content indicated a significantly positive association with trough viscosity $\left(r=0.926^{*}\right)$ and final viscosity $\left(\mathrm{r}=0.917^{*}\right)$. Present data show that peak viscosity had significant and positive relationship with setback $\left(\mathrm{r}=0.879^{*}\right)$ and trough viscosity $\left(\mathrm{r}=0.976^{* *}\right)$.
\end{abstract}

Novelty statement. Pasting properties determine end use quality of wheat flour and primarily relates to starch content of wheat flour, which is present in largest proportion. In Pakistan, various wheat cultivars are grown in different climate. As a result, the variations in physico-chemical as well as rheological properties of wheat varieties is anticipated. Significant correlations found out in present study are valuable for the evaluation of effect of pasting properties alone and their interaction.

Keywords: starch, rapid visco analyzer, pasting properties, correlation

\section{Introduction}

Starch is most imperative carbohydrate in human diet (Kumar and Prabhasankar, 2013) since, cereal grains store energy in form of starch (Panhwar et al., 2014; Belderok et al., 2000). Cultivars having high starch are desired for multi purposes (Buriro et al., 2012). Wheat kernel is primarily composed of endosperm, bran and germ, while inner endosperm consists of starch granules $(65-75 \%)$ and protein $(8-20 \%)$ on dry weight basis (Yu et al., 2015). Starch mainly comprised $67-68 \%$ of whole wheat kernel and $78-82 \%$ of flour that is made of $26-$ $28 \%$ amylose and $72-74 \%$ amylopectin (El-Porai et al., 2013).

Pasting properties are important functional attributes of starch (Tsakama et al., 2010). When an aqueous starch suspension is subjected to heating above certain temperature, the starch granules tend to swell irreversibly due to leaching of amylose into aqueous phase, leading to rise in viscosity (Brabet et al., 1998). It is closely associated with end quality of numerous bakery products (Ragaee and Aal, 2006). Nonetheless, pasting properties

*Author for correspondence;

E-mail: ayeshahaq06@gmail.com of flour not only related to starch but also affected by other flour constituents such as protein, lipid, pentosans and also possibly due to sugar, salt and $\alpha$-amylase activity (El-Porai et al., 2013). Wheat quality is affected by different milling, chemical, rheological and baking properties along with type of cultivar, climate, crop year, harvest and storage conditions (Channa et al., 2015; Amjad et al., 2010).

Rapid Visco Analyser (RVA) is currently used as a tool to ascertain biophysical characteristics of starch. It has been widely used in cereal industry to determine the influence of sprouting on grain quality at delivery point. In recent times, application of RVA has been extended in breeding programs and varietal selection. In Pakistan, various wheat cultivars are grown in different climate. As a result, the variations in physicochemical as well as rheological properties of wheat varieties is anticipated. Pasting properties determine end use quality of wheat flour and primarily relates to starch content of wheat flour, which is present in largest proportion. Current study is aimed to characterize wheat varieties for starch and pasting properties and evaluation of their correlation. 


\section{Materials and Methods}

Materials. Commercially available wheat varieties were procured from Wheat Research Institute, Ayub Agricultural Research Institute (AARI), Faisalabad, Punjab and Wheat Research Institute Sakrand, Nawabshah, Sindh, Pakistan. All chemicals (analytical grade) were purchased from local market.

Starch content. Starch content in wheat flour was determined following AACC method no. 76-13 (AACC, 2000) with slight modification. $0.1 \mathrm{~g}$ accurately weighed flour sample of each variety was added to a glass test tube. For the dispersion of sample, $0.2 \mathrm{~mL}$ of aqueous ethanol was added and tubes were stirred using vortex mixer. Right after this, $3 \mathrm{~mL}$ of content of bottle 1 (thermostable $\alpha$-amylase) was introduced followed by incubation in a boiling water bath with vigorous stirring for $6 \mathrm{~min}$. Then, tubes were again kept at $50{ }^{\circ} \mathrm{C}$ in a water bath, and $0.1 \mathrm{~mL}$ of the contents of bottle 2 were added. The stirring of tube was carried out through vortex mixer and incubation at $50{ }^{\circ} \mathrm{C}$ for $30 \mathrm{~min}$. The volume of the contents of test tubes was made up to $100 \mathrm{~mL}$ and centrifuged at 2,000 rcf for $10 \mathrm{~min}$. For assay, clear and undiluted filtrate was used. Now, 3.0 $\mathrm{mL}$ of GOPOD reagent was added in all tube including D-glucose control and reagent blank, and tubes were incubated at $50{ }^{\circ} \mathrm{C}$ for $20 \mathrm{~min}$. The absorbance of samples and D-glucose control was recorded at $510 \mathrm{~nm}$ against reagent blank.

Pasting properties. Pasting properties of wheat flour were determined by following the method no. 76-21 as described in AACC (2000). To evaluate pasting properties, a starch suspension of $3.5 \mathrm{~g}$ flour sample in $25 \mathrm{~mL}$ distilled water was subjected to a controlled heating and cooling cycle using Rapid Visco Analyzer (Super 4 Newport Scientific Ltd. Australia). Pasting parameters studied were pasting temperature, peak time, peak viscosity, trough viscosity, final viscosity, breakdown viscosity and setback viscosity.

Statistical analysis. All the analyses were conducted in triplicate and results were reported as mean \pm standard error. Significant variations among wheat varieties were evaluated through Analysis of Variance (ANOVA) under Completely Randomized Design (CRD) following the method described by Montgomery (2008) using different statistical software like SPSS version (version 13, 2004) and Minitab (version 11.2, 1996). Relationship of different pasting parameters with starch was determined by Pearson's correlation coefficient.

\section{Results and Discussion}

Starch content. Table 1 lists mean values for starch content in wheat varieties ranging from 68.88 to $72.73 \%$. Regardless of wheat variety, it is recognized that all the wheat varieties tested in present study were statistically similar with respect to starch content. In parallel, starch content of numerous wheat varieties of Sindh was found to be in range of $61.03-75.83 \%$ as stated earlier (Channa et al., 2015; Panhwar et al., 2014; Buriro et al., 2012). However, in contrast to these results, low values (66.17$66.43 \%$ ) of starch were found previously by Bashir et al. (2013) and Mahmood et al. (2013). Level of starch present in wheat grain may range from 60 to $70 \%$ of total dry grain weight (Belderok et al., 2000).

Pasting properties. Mean values for pasting temperature (Table 1) could be observed to vary in a quite narrow range from 65.25 to $67.80^{\circ} \mathrm{C}$. It is believed that wheat varieties investigated in present study are more likely to cause variations in pasting parameters. However, wheat varieties were all the same with respect to pasting temperature. Present results regarding pasting properties are well supported by previous studies (Jagannadham et al., 2014; Kaur et al., 2013; Jian-sheng et al., 2012).

Table 1. Pasting properties of wheat varieties

\begin{tabular}{lllllllll}
\hline \hline Varieties & \multicolumn{7}{c}{ Mean \pm SE } \\
\cline { 2 - 8 } & Starch (\%) & PaT $\left({ }^{\circ} C\right)$ & PT (min) & PV (cP) & TV (cP) & FV $(c P)$ & BV $(c P)$ & SV $(c P)$ \\
\hline FSD-08 & $70.27 \pm 1.86^{\mathrm{a}}$ & $66.90 \pm 1.78^{\mathrm{a}}$ & $4.33 \pm 0.12^{\mathrm{c}}$ & $1496 \pm 52.32^{\mathrm{c}}$ & $795 \pm 20.78^{\mathrm{c}}$ & $2002 \pm 75.09^{\mathrm{cd}}$ & $701 \pm 19.54^{\mathrm{b}}$ & $1207 \pm 39.97^{\mathrm{b}}$ \\
Lasani-08 & $71.91 \pm 1.87^{\mathrm{a}}$ & $66.95 \pm 1.74^{\mathrm{a}}$ & $3.47 \pm 0.09^{\mathrm{c}}$ & $1624 \pm 59.70^{\mathrm{c}}$ & $905 \pm 26.63^{\mathrm{c}}$ & $2135 \pm 78.21^{\mathrm{c}}$ & $719 \pm 20.66^{\mathrm{c}}$ & $1230 \pm 41.97^{\mathrm{b}}$ \\
AARI-11 & $72.23 \pm 1.96^{\mathrm{a}}$ & $67.80 \pm 1.76^{\mathrm{a}}$ & $3.22 \pm 0.09^{\mathrm{b}}$ & $1784 \pm 68.85^{\mathrm{c}}$ & $1002 \pm 32.00^{\mathrm{d}}$ & $2565 \pm 95.55^{\mathrm{d}}$ & $782 \pm 22.97^{\mathrm{b}}$ & $1563 \pm 73.97^{\mathrm{b}}$ \\
T.D-1 & $68.88 \pm 1.79^{\mathrm{a}}$ & $65.25 \pm 1.85^{\mathrm{a}}$ & $6.00 \pm 0.16^{\mathrm{a}}$ & $1330 \pm 49.17^{\mathrm{b}}$ & $645 \pm 16.60^{\mathrm{b}}$ & $1799 \pm 72.15^{\mathrm{b}}$ & $685 \pm 17.28^{\mathrm{a}}$ & $1154 \pm 39.74^{\mathrm{a}}$ \\
Benazir-13 & $69.92 \pm 1.98^{\mathrm{a}}$ & $66.73 \pm 1.81^{\mathrm{a}}$ & $5.73 \pm 0.16^{\mathrm{a}}$ & $1435 \pm 50.57^{\mathrm{a}}$ & $740 \pm 18.30^{\mathrm{a}}$ & $1952 \pm 73.84^{\mathrm{a}}$ & $695 \pm 18.70^{\mathrm{a}}$ & $1212 \pm 40.43^{\mathrm{a}}$ \\
\hline \hline
\end{tabular}

Means carrying same letter within a column are statistically non-significant $(\mathrm{P}>0.05) ; \mathrm{PaT}=($ Pasting temperature $) ; \mathrm{PT}=(\mathrm{Peak}$ time $) ; \mathrm{PV}=($ Peak viscosity $) ; \mathrm{TV}=($ Trough viscosity $) ; \mathrm{FV}=($ Final viscosity $), \mathrm{BV}=($ Breakdown viscosity $), \mathrm{SV}=(\mathrm{Setback}$ viscosity). 
Temperature necessary to start beginning of gelatinization and final viscosity is also related to starch retrogradation, which decreases as the starch gets damage more. Gelatinization behaviour of starch in wheat depends on $\alpha$-amylase activity and can be used to predict baking quality (Channa et al., 2015).

During first holding phase, flour-gum paste was subjected to heating at $95{ }^{\circ} \mathrm{C}$ for $30 \mathrm{~min}$. Inverse of viscosity change before and after this phase provides cooking or heating stability of mixture and greater values are consideration of increased heating stability. While, inverse of viscosity change before and after second holding stage is linked with flour's cooling stability, where paste was allowed to set at $50{ }^{\circ} \mathrm{C}$ for duration of 10 min (Alam et al., 2009). In this context, Barrera et al. (2013) evaluated the impact of starch damage on pasting profile of starch suspensions and deduced that pasting temperature increased with increasing the level of damaged starch.

Peak time in wheat varieties varied from 3.22 to 6.00 min (Table 1). In a study conducted by Nasir (2015), it was reported that peak time was non-significantly affected by quinoa lines and ranged from 6.97 to 6.99 min. Pasting parameters of starch are usually thought to be measured through relation of starch structural properties, involving starch morphology and rigidity (Yu et al., 2015) and are largely affected by milling process (Dhital et al., 2010).

Peak viscosity can be observed to be varied from 1330 to $1784 \mathrm{cP}$. Peak viscosity of whole wheat flour is influenced by wheat variety and environment. Variation in flour peaks of wheat lines were due to differences in amylase activity (Farooq et al., 2001), which is in accord with El-Porai et al. (2013) who stated the difference in RVA viscosity of wheat flour may relate to variations in damaged starch and alpha-amylase activity. A more possible explanation may be the fact that peak viscosity tend to decline with increased damaged starch and $\alpha$-amylase activity. Peak viscosity, which is consideration of swelling behaviour of starch granules, is mostly related to amylopectin, whereas amylose or amyloselipid network may possibly dilute or impede granule swelling thus, decreasing peak viscosity (Wang and Copeland, 2012). Protein strengthens relations between dispersed and continuous phase which gives higher strength towards shearing (Fitzgerald et al., 2003).

Trough viscosity can be observed from Table 1 , in the range of 645-1002 cP. However, El-Porai et al. (2013) reported that trough viscosity of Egyptian wheat ranged 1361-2772 (normal milling) and 1235-2534 cP (hard milling) at different conditioning time (h). Also, with increasing conditioning time from 12 to 24 and $36 \mathrm{~h}$ caused a weakening effect on trough viscosity gradually. Granules rupturing due to shearing contributes to trough viscosity. Trough viscosity is controlled by amount of granule swelling, amylose exudation, amylose-lipid network development and furthermore, competition among exudates amylase and remaining starch granules for free water (Kaur et al., 2013).

In present investigation, final viscosity was observed from 1799 to $2565 \mathrm{cP}$. For final viscosity, the last portion of RVA curve determine the rise in viscosity linked with gelation as well as retro-gradation during cooling. As paste cooled down to $50^{\circ} \mathrm{C}$, starch granules attained a final viscosity, because of re-association or retrogradation of amylose (Ragaee and Aal, 2006). El-Porai et al. (2013) rather evaluated that final viscosity in Egyptian wheat ranged from 2552 to 4969 (normal milling) and 2254 to $4236 \mathrm{cP}$ (hard milling).

Breakdown viscosity of wheat varieties indicated variability from 685 to $782 \mathrm{cP}$. Breakdown was found to be associated with stability of starch granules under the influence of high shear condition (Ragaee and Aal, 2006). Breakdown is reduced by protein might due to maintenance of continuous network or consolidation of links between continuous and dispersed phase (Fitzgerald et al., 2003).

Setback viscosity of wheat varieties showed a wide range varying from 1154 to $1563 \mathrm{cP}$. Higher setback may likely due to degree and molecular weight (MW) of amylose leached from starch and gelatinized starch left behind. Data have shown that protein offer some protection against breakdown. It can be infer that products developed from flour exhibiting greater setback viscosity may have higher levels of staling rate since, greater value of setback is linked to higher retro-gradation rate (Kaur et al., 2013).

Correlation studies. All the parameters in present study were evaluated for their interdependence using Pearson's correlation coefficients. Correlation matrix (Table 2) revealed that starch content had a significantly positive association with trough viscosity $\left(r=0.926^{*}\right)$ and final viscosity $\left(\mathrm{r}=0.917^{*}\right)$. From Table 2, peak time can be observed to have positive relations to breakdown $(\mathrm{r}=$ $\left.0.951^{*}\right)$ and setback viscosities $\left(r=0.918^{*}\right)$. Present data show that peak viscosity had significant and positive 
relationship with setback viscosity $\left(r=0.879^{*}\right)$. Similarly, it was highly significantly and positively linked to trough viscosity $\left(\mathrm{r}=0.976^{* *}\right)$. Figure 1 represents a highly significant and positive association reported between breakdown and peak viscosity $(\mathrm{r}=$ $\left.0.985^{* *}\right)$. Figure 2 illustrates that trough and final

Table 2. Correlation matrix for different parameters of wheat varieties

\begin{tabular}{llllllll}
\hline \hline & Starch & PT & PV & TV & FV & BV & SV \\
\hline Starch & 1.00 & & & & & & \\
PT & -0.644 & 1.00 & & & & & \\
PV & 0.860 & 0.849 & 1.00 & & & & \\
TV & $0.926^{*}$ & 0.733 & $0.976^{* *}$ & 1.00 & & & \\
FV & $0.917^{*}$ & 0.840 & $0.985^{* *}$ & $0.974^{* *}$ & 1.00 & & \\
BV & -0.533 & $0.951^{*}$ & 0.857 & 0.723 & 0.815 & 1.00 & \\
SV & 0.787 & $0.918^{*}$ & $0.879^{*}$ & 0.807 & $0.920^{*}$ & $0.871^{*}$ & 1.00 \\
\hline \hline
\end{tabular}

$*=$ significant $(\mathrm{P}<0.05) ; * *=$ highly significant $(\mathrm{P}<0.01)$.

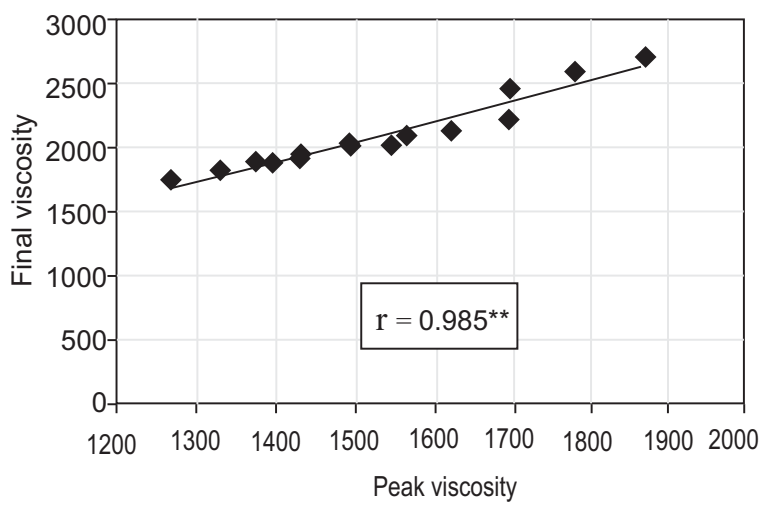

Fig. 1. Correlation between final and peak viscosity of wheat flour.

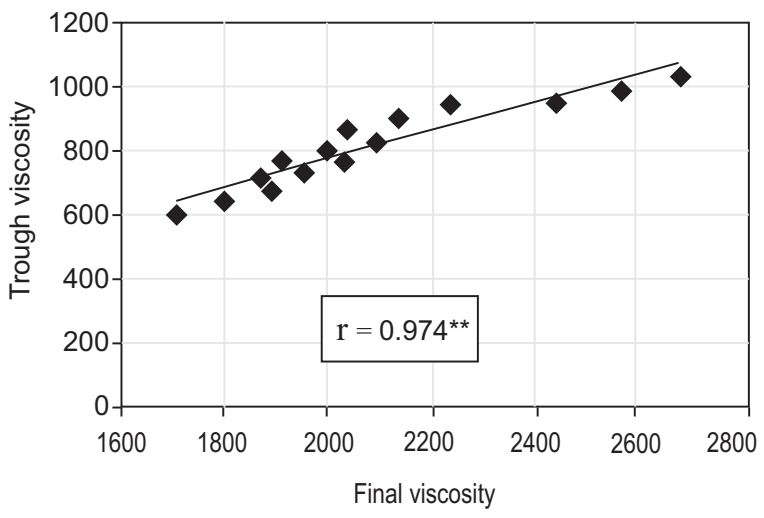

Fig. 2. Correlation between trough and final viscosity of wheat flour. viscosity were found to be positively inter-related $(\mathrm{r}=$ $0.974 * *)$. Likewise, final viscosity had a significant and positive relation with setback viscosity $\left(\mathrm{r}=0.920^{*}\right)$ as shown in Fig. 3. A significant and positive association was found between breakdown and setback $\left(\mathrm{r}=0.871^{*}\right)$ viscosity (Fig. 4). This study comply with Kaur et al. (2013) who observed that peak, final and breakdown viscosities were interconnected to each other. Hence, flour with greater peak viscosity also exhibited higher final and breakdown viscosities.

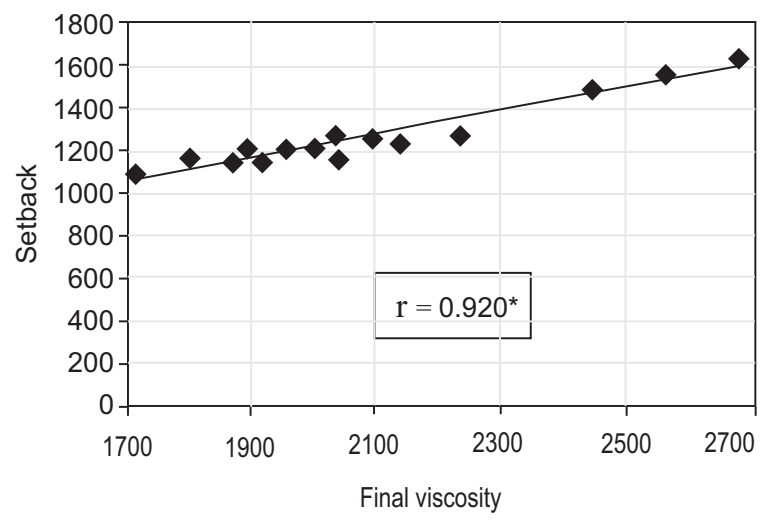

Fig. 3. Correlation between setback and final viscosity of wheat flour.

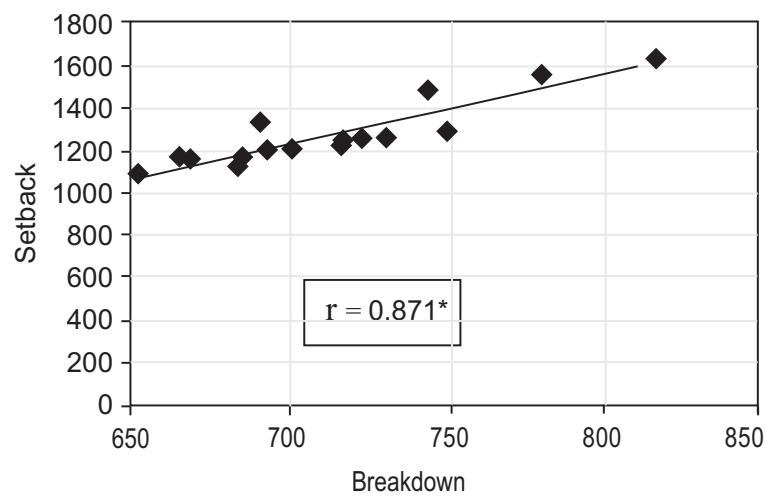

Fig. 4. Correlation between setback and breakdown viscosity of wheat flour.

\section{Conclusion}

In present study, wheat varieties point out significant variations in most of rheological parameters. Out of all wheat varieties, AARI-11 contained highest amount of starch. Likewise, RVA profile indicated that wheat varieties containing higher level of starch also exhibited 
highest pasting properties as well. Pearson's correlation coefficient indicated that there was an association among different pasting properties analyzed through RVA and these attributes were positively correlated to each other. Hence, the knowledge obtained in this piece of work will help out to discriminate wheat varieties with respect to their pasting properties and these varieties may find their appropriate use in different bakery products accordingly.

Conflict of Interest. The authors declare no conflict of interest.

\section{References}

AACC (American Association of Cereal Chemists). 2000. Approved Methods of American Association of Cereal Chemists. $10^{\text {th }}$ edition, St. Paul, Minnesota, USA.

Alam, F., Siddiqui, A., Lutfi, Z., Hasnain, A. 2009. Effect of different hydrocolloids on gelatinization behaviour of hard wheat flour. Trakia Journal of Sciences, 7: 1-6.

Amjad, M., Safdar, M.N., Mumtaz, A., Naseem, K., Raza, S., Khalil, S. 2010. Comparison of different wheat varieties grown in Punjab for leavened flat bread (Naan) production. Pakistan Journal of Nutrition, 9: 146-150.

Barrera, G.N., Bustos, M.C., Iturriaga, L., Flores, S.K., León, A.E., Ribotta, P.D. 2013. Effect of damaged starch on the rheological properties of wheat starch suspensions. Journal of Food Engineering, 116: 233-239.

Bashir, M.H., Mahmood, S.U., Khan, M.A., Afzal, M., $\mathrm{Zia}, \mathrm{K}$. 2013. Estimation of nutritional losses caused by Rhizoglyphus tritici (Acari: Acaridae) in stored wheat. Pakistan Journal of Agricultural Sciences, 50: 631-635.

Belderok, B., Mesdag, J., Donner, D.A. 2000. BreadMaking Quality of Wheat: A Century of Breeding in Europe. pp. 30-31, Kluwer Academic Publisher, Dordrecht, The Netherlands.

Brabet, C., Reynoso, D., Dufour, D., Mestres, C., Arredondo, J., Scott, G. 1998. Starch content and properties of 106 sweetpotato clones from the world germplasm collection held at CIP, Peru. International Potato Centre. Lima, Peru.

Buriro, M., Oad, F.C., Keerio, M.I., Gandahi, A.W., Laghari, G.M. 2012. Impact of storage sources on physico-chemical properties of various wheat varieties. Sarhad Journal of Agriculture, 28: 185190.

Channa, M.J., Ghanghro, A.B., Sheikh, S.A., Nizamani, S.M. 2015. Physico-chemical characteristics and rheological properties of different wheat varieties grown in Sindh. Pakistan Journal of Analytical and Environment Chemistry, 16: 11-18.

Dhital, S., Shrestha, A.K., Gidley, M.J. 2010. Effect of cryomilling on starches: functionality and digestibility. Food Hydrocolloids, 24: 152-163.

El-Porai, E.S., Salama, A.E., Sharaf, A.M., Hegazy, A.I., Gadallah, M.G.E. 2013. Effect of different milling processes on Egyptian wheat flour properties and pan bread quality. Annals of Agricultural Sciences, 58: 51-59.

Farooq, Z., Rehman, S.U., Butt, M.S., Bilal, M.Q. 2001. Suitability of wheat varieties/lines for the production of leavened flat bread (Naan). Pakistan Journal of Scientific and Industrial Research, 12: 171-179.

Fitzgerald, M.A., Martin, M., Ward, R.M., Park, W.D., Shead, H.J. 2003. Viscosity of rice flour-A rheological and biological study. Journal of Agricultural and Food Chemistry, 51: 2295-2299.

Jagannadham, K., Parimalavalli, R., Babu, A.S., Rao, J.S. 2014. A study on comparison between cereal (wheat) and non cereal (chickpea) flour characteristics. International Journal of Current Trends in Research, 3: 70-76.

Jian-sheng, C., Ji-chun, T., Zhi-ying, D., Ying-xiang, Z., Shou-li, F., Zuo-chen, Y., Xin-ye, Z., Hui-qing, Y. 2012. Effects of papain hydrolysis on the pasting properties of wheat flour. Journal of Integrative Agriculture, 11: 1948-1957.

Kaur, A., Singh, N., Ahlawat, A.K., Kaur, S., Singh, A.M., Chauhan, H., Singh, G.P. 2013. Diversity in grain, flour, dough and gluten properties amongst Indian wheat cultivars varying in high molecular weight subunits (HMW-GS). Food Research International, 53: 63-72.

Kumar, S.B., Prabhasankar, P. 2013. Low glycemic index ingredients and modified starches in wheat based food processing: A review. Trends in Food Science and Technology, 35: 32-41.

Mahmood, S.U., Bashir, M.H., Abrar, M., Sabri, M.A., Khan, M.A. 2013. Appraising the changes in the nutritional value of stored wheat, Triticum aestivum L. infested with acarid mite, Rhizoglyphus tritici (Acari: Acaridae). Pakistan Journal of Zoology, 45: $1257-1261$. 
Montgomery, D.C. 2008. Experiments with a single factor, the analysis of variance. In: Design and Analysis of Experiments. $8^{\text {th }}$ edition, John Wiley \& Sons, Inc.

Nasir, M.A. 2015. Nutritional and functional perspectives of quinoa (Chenopodium quinoa L.). Ph.D. Thesis, National Institute of Food Science and Technology, University of Agriculture, Faisalabad, Pakistan.

Panhwar, A.A., Sheikh, S.A., Mirani, B.N., Channa, M.J., Khanzada, S. 2014. Studies on the nutritional characteristics of some commercial wheat varieties of dry land and wet land grown in Sindh province. Journal of Pharmacy and Nutrition Sciences, 4: 263-267.

Ragaee, S., Aal, E.S.M. 2006. Pasting properties of starch and protein in selected cereals and quality of their food products. Food Chemistry, 95: 9-18.

Tsakama, M., Mwangwela, A.M., Manani, T.A., Mahungu, N.M. 2010. Physico-chemical and pasting properties of starch extracted from eleven sweetpotato varieties. African Journal of Food Science and Technology, 1: 090-098.

Wang, S.J., Copeland, L. 2012. Effect of alkali treatment on structure and function of pea starch granules. Food Chemistry, 135: 1635-1642.

Yu, J., Wang, S., Wang, J., Li, C., Xin, Q., Huang, W., Zhang, Y., He, Z., Wang, S. 2015. Effect of laboratory milling on properties of starches isolated from different flour millstreams of hard and soft wheat. Food Chemistry, 172: 504-514. 